\title{
An Evolutionary Software Project Management Maturity Model for Mauritius
}

\author{
Aneerav Sukhoo, Andries Barnard, Mariki M. Eloff, \\ and John A. Van der Poll \\ University of South Africa, Pretoria, South Africa
}

\author{
aneeravsukhoo@yahoo.com barnaa@unisa.ac.za \\ eloffmm@unisa.ac.za vdpolja@unisa.ac.za
}

\begin{abstract}
Software project management is a relatively recent discipline that emerged during the second half of the $20^{\text {th }}$ century (Kwak, 2003). Many of the software project management methodologies available today were developed in Western/European countries and research showed that there was a need to formalise a software project management framework for developing countries, in particular Africa (Muriithi \& Crawford, 2003).

Based on surveys and discussions with software professionals, a methodology for software project management is being proposed. The methodology is based on a maturity model as Mauritius is faced with a shortage in skilled professionals. So far, few organisations in Mauritius have been found to be using software project management methodologies developed in Western/European countries.
\end{abstract}

Most maturity models, for example Capability Maturity Model Integration (CMMI) and Kerzner's maturity model, have five maturity levels. The trend is towards the development of maturity models that have fewer maturity levels. For example, the Organisational Project Management Maturity Model (OPM3) and Prince 2 Maturity Model have been developed with three maturity levels.

Similarly, the proposed Evolutionary Software Project Management Maturity Model (ESPM $\left.{ }^{3}\right)$ has three maturity levels and a continuous process improvement group of key process areas (KPAs). ISO 9001:2000 is chosen as the quality management system and each KPA is mapped onto the plan-do-check-act (PDCA) cycle. The model is conceptually represented as a conical structure to better display the evolutionary development of KPAs. KPAs, which are focus areas to be considered for project management, are developed until they attain maturity at a certain level. As organisations have to be responsive to their environments, these KPAs may require further changes even after they have reached maturity. A continuous process group of KPAs helps in adapting to changes in environment.

Material published as part of this publication, either on-line or in print, is copyrighted by the Informing Science Institute. Permission to make digital or paper copy of part or all of these works for personal or classroom use is granted without fee provided that the copies are not made or distributed for profit or commercial advantage AND that copies 1) bear this notice in full and 2) give the full citation on the first page. It is permissible to abstract these works so long as credit is given. To copy in all other cases or to republish or to post on a server or to redistribute to lists requires specific permission and payment of a fee. Contact Publisher@InformingScience.org to request redistribution permission.
In order to test the proposed methodology, one case study has been included. The application of the methodology to the project could not be discussed in detail in this paper. The development of KPAs in an organisation takes time and the case study was only a snapshot of the application of the methodology. 
Keywords: software project management, software development, maturity model, evolutionary process, project management methodology.

\section{Introduction}

There is ample evidence that the inherent principles of project management have been practiced already for thousands of years (Kwak, 2003). The results are that many human achievements, for example the pyramids of Egypt and the Great Wall of China, are recognised as wonders of the present-day world. It is unfortunate that the Manhattan project (Kwak, 2003), although considered as a successful human undertaking (the development of the atomic bomb) at a later stage caused the loss of lives on a large scale.

Apart from the construction and engineering areas, applied principles of project management made inroads into virtually all avenues of work by encompassing sectors such as the military, social and community development, medicine, agriculture and education to name just a few (Kwak, 2003). Today, the impact of project management is most profound in the area of Information Technology (Gray \& Larson, 2000) where new hardware and software products are constantly flooding the world market. Increased pressure to reduce cost and delivery time in a highly global and competitive environment has given due credit to project management principles, techniques and tools. Software project management, in particular, is an area of research with a view to achieve higher levels of quality and to improve both cost and schedule estimates. This is evident from frequent new releases of project management methodologies like the Project Management Body of Knowledge ${ }^{\circledR}$ (PMBOK ${ }^{\circledR}$ Guide, 2004), PRojects IN Controlled Environment (PRINCE) (Central Computer and Telecommunications Agency [CCTA], 2002) and the Capability Maturity Model Integration (CMMI Product Team, 2002). These methodologies were studied prior to the development of a suitable methodology for Mauritius. A software project management methodology is being proposed since it has been noted that a software project has certain specificities that are different from traditional engineering projects. Hughes and Cotterell (2006) argued in favour of the specificities of managing software projects. Some pertinent differences between software projects and traditional engineering projects were also elaborated on by Sukhoo, Barnard, Eloff and Van der Poll (2004b).

A plethora of project management methodologies is now available and many methodologies are subject to continuous improvement. Project management methodologies are generally generic in nature, in that they cut across various disciplines and are used in many countries. Some studies, for example Muriithi and Crawford (2003) and Stuckenbruck and Zomorrodian (1987), have revealed that such methodologies are not necessarily universally applicable because factors like economic rationalities are too often assumed and legal, political as well as cultural and religious variations occur across nations and cultures. Hofstede's dimensions as applied to African countries (Muriithi \& Crawford, 2003), Kuwait (Aladwani, 2002) as well as Mexico, India and Russia (Rao, 2004) have been discussed in terms of high power distance and high uncertainty avoidance as compared to Western/European countries. Open discussions are not favoured and low tolerance for ambiguities is noted in developing countries. It is plausible to expect that these factors may negatively influence the successful outcome of software projects, particularly in developing economies, as these factors are seldom taken into account by a particular methodology. By and large, developing countries constantly face problems of insufficient skilled staff, funds, and political and social incentives (Muriithi \& Crawford, 2003). Mauritius, for example, is facing such problems at a crucial moment in its history as the Government has embarked on a vision to develop it into a "Cyber Island" while at the same time allowing Information and Communication Technologies (ICT) to emerge as the fifth pillar of the economy besides sugar, tourism, textile and the financial services (Eid, 2002). 
In particular, some of the problems affecting the Mauritian IT sector are:

- lack of skilled human resources (BPO Secretariat, 2005)

- $\quad$ high labour mobility (BPO Secretariat, 2005)

- lack of training (BPO Secretariat, 2005)

- ageing population

- unstable economic situation (Muriithi \& Crawford, 2003)

- methodologies of Western/European origins are not completely suitable and are too expensive to adopt for most organizations (Muriithi \& Crawford, 2003)

- lack of management commitment

- lack of soft skills in management of projects

- organizations are characterised by tall hierarchical structures (Muriithi \& Crawford, 2003)

- existing methodologies are considered to be too bureaucratic.

This paper aims to address some of the problems faced by Mauritius through the application of an evolutionary software project management maturity model $\left(\mathrm{ESPM}^{3)}\right.$ to the management of software projects. This methodology, being a streamlined one and aiming at simplifying software project management, may also be extended to other developing countries given that the problems identified are common and confirmed according to the research conducted by Muriithi and Crawford (2003). It is anticipated that this $\mathrm{ESPM}^{3}$ will assist organizations by adopting a progressive implementation of various processes.

The layout of this paper is as follows: we present a discussion on the unsuitability of two popular project management methodologies namely $\mathrm{PMBOK}^{\circledR}$ and CMMI in a developing country context, particularly for Mauritius. The results of a survey/interview focusing at gathering information to be used in a software project management methodology for developing countries are discussed in the next section. Then, we introduce an evolutionary software project management maturity model $\left(\mathrm{ESPM}^{3}\right)$ and show how the methodology addresses some of the problems faced by Mauritius as a developing economy in particular. We conclude with an analysis and some pointers to future work.

\section{Unsuitability of PMBOK ${ }^{\circledR}$ and CMMI for Mauritius}

We speculate on the unsuitability of $\mathrm{PMBOK}^{\circledR}$ and $\mathrm{CMMI}$ for Mauritius. The $\mathrm{PMBOK}^{\circledR}$ Guide does mention that a project team should consider a project in the context of political, economic, demographic and cultural norms, but it does not explain how or when to handle them. The PMBOK $^{\circledR}$ Guide, furthermore, increased the number of pages from around 200 to around 400 since the previous release. The number of processes involved also increased from 39 to 44, thereby adopting a rather complex systems view of project management in general, and software project management in particular (Wideman, 2005). Specifically, small projects can be affected by the number of processes involved. The project team may, therefore, be overloaded by the number of process areas. In Mauritius, the lack of skilled software developers within organizations coupled with high labour mobility has a marked influence on the applicability of PMBOK ${ }^{\circledR}$.

CMMI provides progressive improvements of organizational maturity by achieving maturity at a pre-defined level before advancing to a higher level. Hence, the project team focuses on a restricted set of process areas to reach a maturity level. However, CMMI does not assist in the management of influences brought about by social, economic or environmental pressures as well as human resource problems. In addition, the methodology incorporates a sheer volume of documentation of over 600 pages that increases the learning duration. Given that the interaction with human beings is important for a successful software development process, CMMI alone cannot address the human resource management problem. In Mauritius, not many companies can afford 
to adopt CMMI given the high initial cost of training required. Thus far, only one Mauritian organization is using this methodology (State Informatics Ltd Website, 2006).

Although the sheer volume of documentation of $\mathrm{PMBOK}^{\circledR}$ and $\mathrm{CMMI}$ was meant to improve the methodologies, most Mauritian companies have not been able to take advantage of them as the number of skilled personnel and funds for training are not sufficient.

According to the survey on project management tools, techniques and methodologies used in Mauritius (Sukhoo, Barnard, Eloff, \& Van der Poll, 2004a), it was observed that there was resistance to use methodologies of Western/European origin. This is also in line with the research conducted by Muriithi and Crawford (2003).

In the next section we discuss a survey conducted in Mauritius to gather information to assist in the development of a software project management model followed by a description of the proposed model referred to as the Evolutionary Software Project Management Maturity Model $\left(\mathrm{ESPM}^{3}\right)$. It is presented as a simple and flexible methodology aimed at incorporating minimal bureaucratic procedures.

\section{Survey/Interview Conducted in Mauritius}

Two surveys were conducted, one on project management tools, techniques and methodologies used in Mauritius (Sukhoo et al., 2004a) and the other on software project maturity in Mauritius (Sukhoo, Barnard, Eloff, \& Van der Poll, 2005b). In addition, a recent combined survey/interview (questionnaire is found in the Appendix) was conducted with 11 pertinent software development organizations in Mauritius during the period July to August 2006 with the aim at gathering information on KPAs, that is focus areas to be considered during management of software projects. All the respondents agreed on the applicability of a maturity model with less than 5 maturity levels for Mauritius. It is argued that a maturity model may hide certain deficiencies, but an organization is free to consider all KPAs for the proposed maturity model. The different levels help an organization to concentrate on certain KPAs at a level until it attains maturity. Then, the next level is considered. Organisations are able to identify their strengths and weaknesses and consider their areas of improvement. In the case of CMMI, which has 5 maturity levels, not many organizations in the world have reached the highest level. Therefore, the proposed model is meant to allow all Mauritian software development organizations to attain the highest level in the shortest time possible in order to develop the Information and Communication Technologies sector. Even the recently developed PRINCE 2 maturity model has adopted less than 5 levels. Three maturity levels (level 1 to 3 ) together with a set of continuous improvement key process areas were identified to be the most appropriate number of maturity levels. Key Process Areas (KPAs) to achieve a particular maturity level were also identified and eventually classified in different maturity levels.

A list of KPAs was provided in the questionnaire and most respondents agreed to its applicability. In this context, the most applicable KPAs identified in the Mauritian context were found to be the following:

- Time management

- Cost management

- Quality management

- Human Resource management

- Risk management

- Soft skills management

- Contract management

- Change management

- Software specific focus 
- Integration management

- Environmental management

The respondents' classification of the KPAs into levels was as per Table 1:

Table 1: Survey/Interview results for classification of KPAs

\begin{tabular}{|l|c|c|c|c|l|}
\hline & \multicolumn{3}{|l|}{$\begin{array}{l}\text { Respondents classification of } \\
\text { KPA's at the different levels }\end{array}$} & $\begin{array}{l}\text { Total no } \\
\text { of re- } \\
\text { spondents }\end{array}$ & $\begin{array}{l}\text { Percentage } \\
\text { response }\end{array}$ \\
\cline { 2 - 6 } & Level 2 & Level 3 & $\begin{array}{l}\text { Continu- } \\
\text { ous proc- } \\
\text { ess im- } \\
\text { prove- } \\
\text { ment }\end{array}$ & & \\
\hline Time management & 8 & 0 & 3 & 11 & $100 \%$ \\
\hline Cost management & 5 & 2 & 3 & 10 & $91 \%$ \\
\hline Quality management & 7 & 1 & 3 & 11 & $100 \%$ \\
\hline $\begin{array}{l}\text { Human resource manage- } \\
\text { ment }\end{array}$ & 1 & 7 & 2 & 10 & $91 \%$ \\
\hline Risk management & 2 & 7 & 1 & 10 & $91 \%$ \\
\hline Soft skills management & 2 & 3 & 5 & 10 & $91 \%$ \\
\hline Contract management & 2 & 7 & 0 & 9 & $82 \%$ \\
\hline Change management & 1 & 3 & 7 & 11 & $100 \%$ \\
\hline Software specific focus & 3 & 1 & 6 & 10 & $91 \%$ \\
\hline Integration management & 0 & 1 & 10 & 11 & $100 \%$ \\
\hline Environmental management & 9 out of 11 mentioned that a KPA dealing & $82 \%$ \\
\hline & \multicolumn{2}{|l|}{ with cultural, political and economic } & \\
\hline
\end{tabular}

It was noted that some respondents did not provide any classification for some KPAs. It can, however, be noted that above $80 \%$ of responses were received for classification of KPAs. For Time management, 8 respondents mentioned that the KPA had to be considered at level 2, no respondent mentioned that the KPA had to be at level 3 and 3 respondents mentioned that the KPA had to be classified into the continuous process improvement group. Therefore, Time management was considered as a maturity level $2 \mathrm{KPA}$ (that is, the level at which the majority of respondents agreed that the KPA should be). The continuous process improvement group, however, comprises KPAs that need to be taken into consideration at all maturity levels (at least informally at level 1 as well).

According to the above-mentioned combined survey/interview as well as the 2004 (Sukhoo et al., $2005 \mathrm{~b}$ ) survey, the key process areas identified were categorised into two levels (2 and 3 ) as mentioned previously. Other KPAs were found to be important at all levels and they act as factors, which triggered improvements for KPAs at both levels 2 and 3. For instance, Change management can have an impact on the Time management KPA in case political pressure is exerted to motivate project delivery before the scheduled time. 
The different KPAs are therefore grouped into maturity levels as shown in Table 2.

Table 2: KPAs grouped in maturity levels

\begin{tabular}{|l|l|}
\hline KPA & Maturity level \\
\hline Time management & 2 \\
\hline Cost management & 2 \\
\hline Quality management & 2 \\
\hline Human resource management & 3 \\
\hline Risk management & 3 \\
\hline Soft skills management & Continuous process improvement group \\
\hline Contract management & 3 \\
\hline Change management & Continuous process improvement group \\
\hline Software specific focus & Continuous process improvement group \\
\hline Integration management & Continuous process improvement group \\
\hline Environmental management & Continuous process improvement group \\
\hline
\end{tabular}

Most of the above KPAs were also considered important success factors in a previous study conducted in Mauritius (Sukhoo et al., 2005b).

Furthermore, each KPA is mapped onto four process groups as per ISO 9001:2000 (Mauritian Standard, 2001) requirements as follows:

(i) Plan: Establish the objectives and processes necessary to deliver results in accordance with customer requirements and organizational policies.

(ii) Do: Implement the processes.

(iii) Check: Monitor and measure processes and products against policies, objectives and requirements and report the results.

(iv) Act: Take actions to continually improve process performance.

ISO 9001:2000 was adopted as the quality management standard for our proposed ESPM ${ }^{3}$ because many organizations in Mauritius are already following this standard (Management Audit Bureau Website, 2005).

Following the identification and grouping of the KPAs into different maturity levels, a conical structure is used to represent the maturity levels comprising these KPAs in the next section.

\section{The Evolutionary Software Project Management Maturity Model (ESPM $\left.{ }^{3}\right)$}

The conceptual representation of the proposed ESPM ${ }^{3}$ adopts a conical structure with three defined levels (maturity levels 1 to 3), depicted in Figure 1. The conical structure has been chosen as it better displays the evolutionary development of the KPAs. 


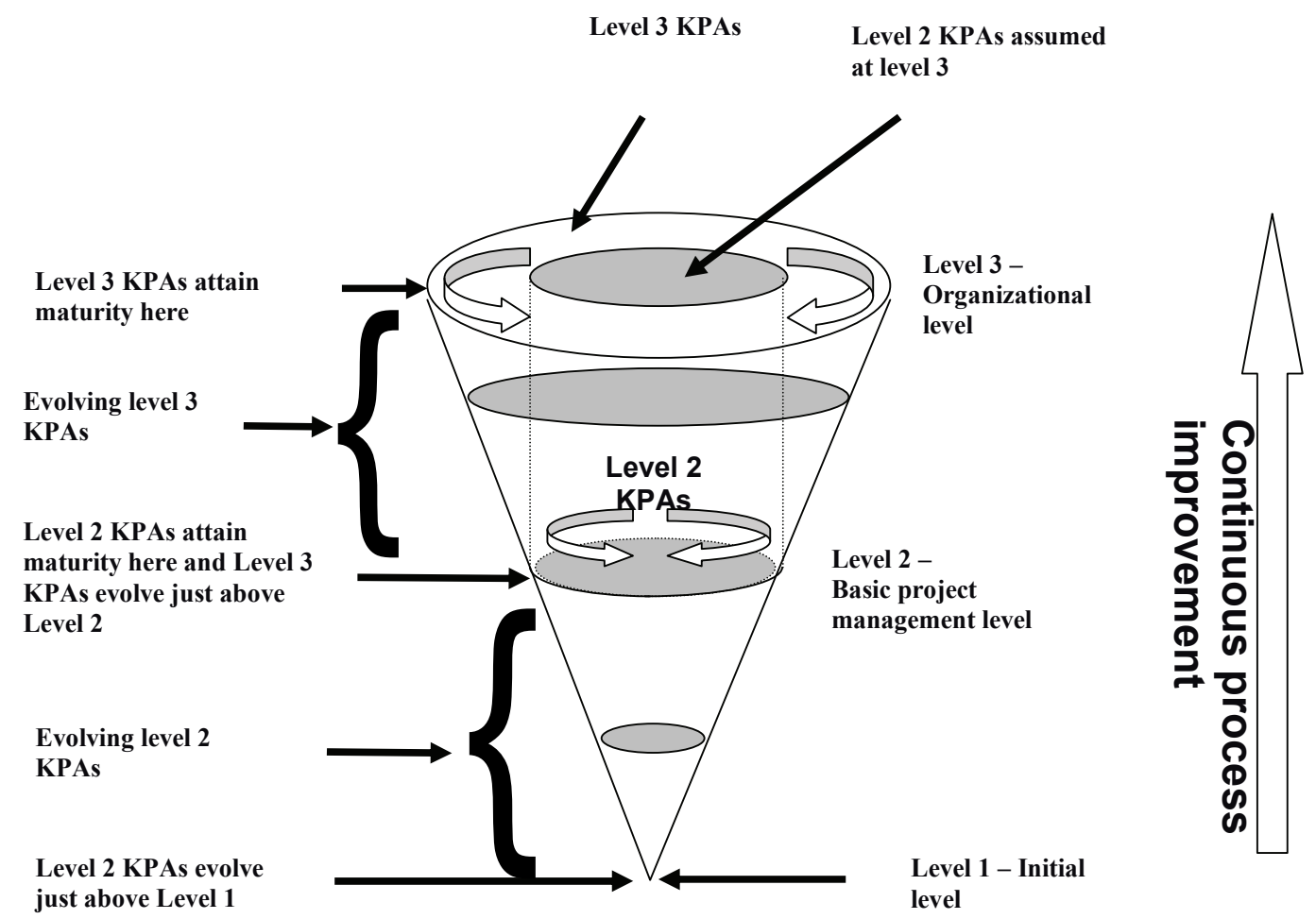

Figure 1: Conceptual Representation of ESPMMM

Maturity levels 2 and 3 each consist of a number of KPAs, which are focus areas in order to achieve the respective maturity level. Maturity level 1 is the initial level of our model and has no KPAs associated with it since software development at this level is carried out in an ad-hoc manner. In other models this level is often considered as the "chaotic" level. The KPAs at levels 2 and 3 are represented conceptually as sectors on the horizontal section of the cone (Figure 7). KPAs at a specified maturity level are assumed at higher levels. For example at maturity level 3, a cross section of the cone reveals the KPAs at level 2 as well as the new KPAs at level 3. Note, however, that the pictorial representation of an area of a sector is not representative of the amount of effort required to implement a specific KPA.

Specific to problems identified in some Mauritian software development companies, a range of key process areas was identified to be implemented at the various maturity levels introduced above. Specific shortcomings pertaining to some or all of these KPAs were identified during surveys conducted in Mauritius in 2003 (Sukhoo et al., 2004a) and 2004 (Sukhoo et al., 2005b). In $2003,50 \%$ of Mauritian software development companies mentioned that more than $50 \%$ of their projects failed to meet deadlines, $30 \%$ of companies mentioned that more than $10 \%$ of their projects suffered from budget overruns and $10 \%$ of companies pointed out that more than $75 \%$ of their projects did not satisfy the users with regard to quality. Risk management, inappropriate project team, poor planning, lack of skilled professionals, mobility of labour, communication problems among team members as well as with clients, and the lack of an appropriate methodology were among several problems that were encountered. Furthermore, the Risk management KPA was not adequately addressed, since most companies surveyed at that point in time remained at maturity level 1. 


\section{Representation of KPAs throughout the Evolutionary Process}

There are some KPAs that are not tied to a specific maturity level but need to be considered throughout the evolutionary process. This continuous improvement group of processes spans over all three levels. The continuous improvement process group, $\mathrm{M}_{\mathrm{c}}$, is defined generally as the union of a number of KPAs.

$$
\mathrm{M}_{\mathrm{c}}=\bigcup_{\mathrm{k}=1}^{\mathrm{p}} \mathrm{KPA}_{\mathrm{ck}}
$$

where $\mathrm{p}$ is the total number of KPAs in the continuous process improvement group. A KPA in $\mathrm{M}_{\mathrm{c}}$ is identified by adding the subscript "c" to the specific KPA, for example $\mathrm{KPA}_{\mathrm{cl}}$ is the first KPA in $\mathrm{M}_{\mathrm{c}}$.

For ESPM ${ }^{3}$ we identify 5 KPAs that need to be considered at all maturity levels. This selection is based on, amongst other things, respondent classifications of the KPAs as per the questionnaire (refer to Table 1). These KPAs are:

- Soft skills management $\left(\mathrm{KPA}_{\mathrm{cl}}\right)$

- Change management $\left(\mathrm{KPA}_{\mathrm{c} 2}\right)$

- Software specific focus $\left(\mathrm{KPA}_{\mathrm{c} 3}\right)$

- Integration management $\left(\mathrm{KPA}_{\mathrm{c} 4}\right)$

- Environmental management $\left(\mathrm{KPA}_{\mathrm{c} 5}\right)$.

The above KPAs are expected to influence all other KPAs and induce continuous improvement. They are represented by the arrow on the right in Figure 2.

The Environmental management KPA is concerned with specific social, cultural, political and economic factors for Mauritius. These factors were found to affect software project management. For example, a project deemed to offer certain political benefits need to be given high priority and must be managed with extreme care. In managing the environmental factors, the following inputs are transformed into outputs:

- List of environmental factors to be addressed (for example political, social, cultural and economic benefits so that such projects are given priority). An example of such a project is treated in the case study.

- List of ways to deal with the factors (for example, assigning skilled human resources and technology)

- Historical data.

The transformation yields the following outputs:

- Satisfied team members and stakeholders

- Safe software development environment (for example, other projects must not fail due to political, social and economic priorities)

- Lessons learnt. 


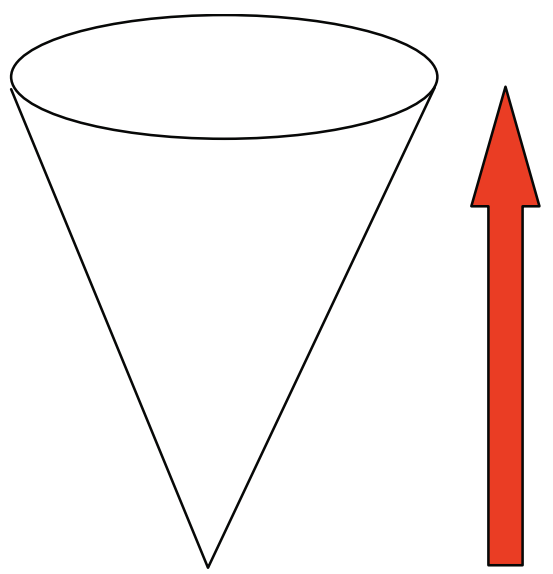

Figure 2: Continuous process improvement

The continuous improvement process group for $\mathrm{ESPM}^{3}, \mathrm{M}_{c}$, is the union of Soft skills management $\left(\mathrm{KPA}_{\mathrm{cl}}\right)$, Change management $\left(\mathrm{KPA}_{\mathrm{c} 2}\right)$, Software specific focus $\left(\mathrm{KPA}_{\mathrm{c} 3}\right)$, Integration management $\left(\mathrm{KPA}_{\mathrm{c} 4}\right)$, and Environmental management $\left(\mathrm{KPA}_{\mathrm{c} 5}\right)$.

Instantiating $\mathrm{p}$ in formula (1) above for the number of KPAs at this level, the continuous improvement process group for $\mathrm{ESPM}^{3}$ is given by:

$$
\mathrm{M}_{\mathrm{c}}=\bigcup_{\mathrm{k}=1}^{5} \mathrm{KPA}_{\mathrm{ck}}
$$

\section{Maturity Level 1}

Maturity level 1 is the initial level in the proposed model, as shown in Figure 3.

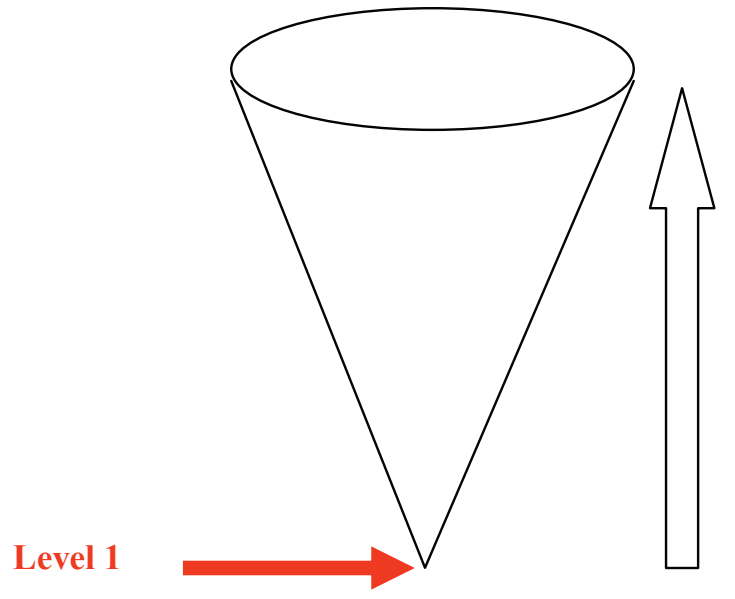

Figure 3: Maturity level 1

At this level, no KPAs are defined. The software development process is carried out in an ad-hoc (chaotic) manner similar to other maturity models and project success depends on the project team. A change in the project team while the project is in progress may disrupt its execution as the skills and processes used are not consistent among project teams. The operation of an organi- 
zation at level 1 involves uncalculated risks and progress towards level 2 is necessary. Maturity level 1 , namely $\mathrm{M}_{1}$, contains no KPAs, that is $\mathrm{M}_{1}=\varnothing$ or it is the null set.

\section{Maturity Level 2}

This level provides a basic project management focus, which is important for the software development process, since it forms the foundation for level 3. It is referred to as the basic project management level. Figure 4 depicts level 2 as a horizontal section of the cone.

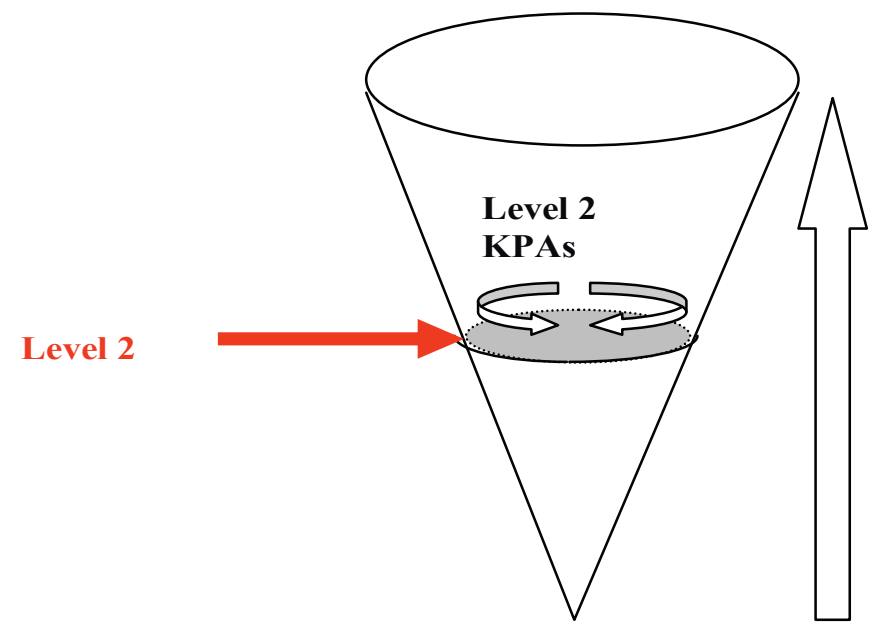

Figure 4: Maturity level 2

Maturity level 2, namely $\mathrm{M}_{2}$, is the union of all KPAs at level $1\left(\mathrm{M}_{1}\right)$, all KPAs at the current level and the continuous improvement process group of $\mathrm{KPAs}\left(\mathrm{M}_{\mathrm{c}}\right)$, that is

$$
M_{2}=M_{1} \cup \underset{j=1}{\bigcup} \mathrm{KPA}_{2 \mathrm{j}} \quad \mathrm{U} \quad \mathrm{M}_{\mathrm{c}}
$$

$\mathrm{M}_{1}$ and $\mathrm{M}_{\mathrm{c}}$ are given by (3) and (1) respectively and $\mathrm{n}$ is the total number of KPAs at level 2.

Figure 5 shows graphically how the KPAs (say n KPAs) at level 2 are represented as a view from the top of the cone. In addition the continuous improvement group of KPAs, $\mathrm{M}_{c}$, influences the level 2 KPAs.

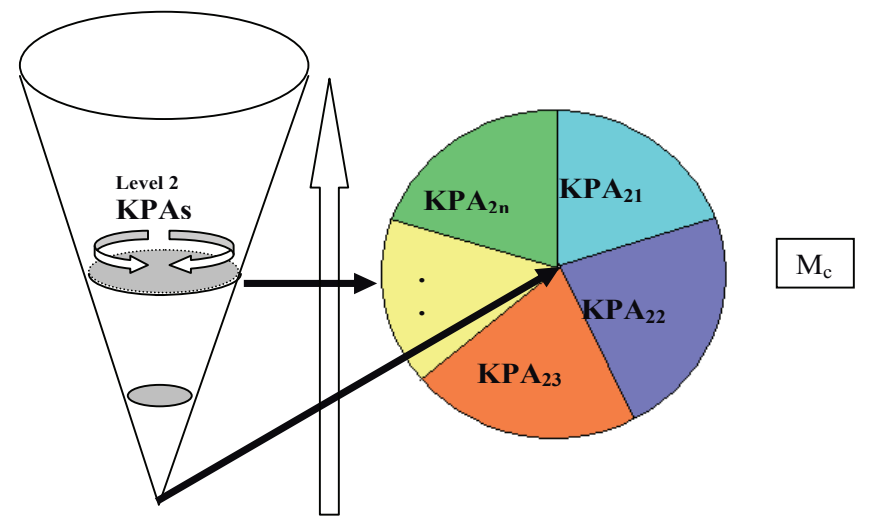

Figure 5: Conceptual Representation of $n$ KPAs at level 1 and 2 
Assuming a maturity level with n KPAs, each one is represented as a sector by viewing the appropriate horizontal section of the cone. At a specified maturity level, its associated KPAs are considered to have evolved fully and do not require further development at any of the higher levels except for continuous process improvement where improvement is required for the process to adapt to the dynamic environment in which organizations evolve.

A KPA at level 2 is indicated as $\mathrm{KPA}_{2 \mathrm{i}}$, for example, $\mathrm{KPA}_{23}$ is the third KPA at maturity level 2. Only the essential KPAs for the basic project management level are selected based, among other things, on the respondent classification in the survey conducted in order to encourage organizations to progress rapidly to level 2 and ensure that an acceptable number of projects are delivered on time, within budget and according to a specified quality standard. In this context for ESPM ${ }^{3}$, and based on respondent classifications (see Table 1), three KPAs are chosen to achieve this level, and they are:

- Time management: to ensure timely delivery of projects $\left(\mathrm{KPA}_{21}\right)$

- Cost management: to deliver projects within budget $\left(\mathrm{KPA}_{22}\right)$

- Quality management: to deliver projects according to ISO 9001:2000 standards $\left(\mathrm{KPA}_{23}\right)$ and to meet customer requirements.

Substituting for $\mathrm{n}$ in formula (3) and for $\mathrm{M}_{1}=\varnothing, \mathrm{M}_{2}$ for $\mathrm{ESPM}^{3}$ is defined as

$$
M_{2}=\underset{j=1}{\bigcup} \mathrm{KPA}_{2 \mathrm{j}} \quad \mathrm{U} \quad \mathrm{M}_{\mathrm{c}}
$$

\section{Maturity Level 3}

This level provides an organizational focus. Maturity level 3, $\mathrm{M}_{3}$, is the union of all KPAs at level 3 and level $2\left(\mathrm{M}_{2}\right)$, where $\mathrm{M}_{2}$ already includes the continuous improvement process group of KPAs $\left(M_{c}\right)$. This level is shown in Figure 6.

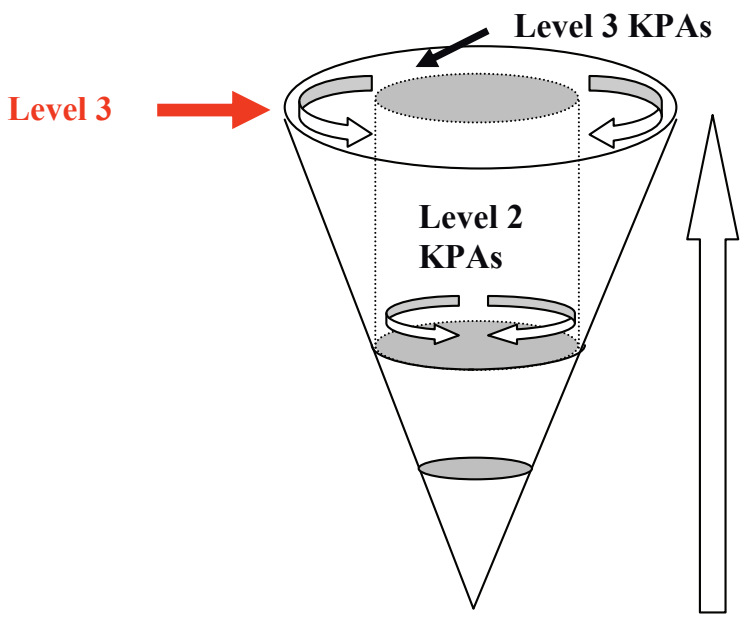

Figure 6: Maturity level 3 
Therefore,

$$
\mathrm{M}_{3}=\bigcup_{\mathrm{i}=1}^{\mathrm{m}} \mathrm{KPA}_{3 \mathrm{i}} \quad \mathrm{U} \quad \mathrm{M}_{2}
$$

where $\mathrm{m}$ is the total number of KPAs at level 3 (the $\mathrm{KPA}_{3}$ 's) and $\mathrm{M}_{2}$ is given by (4).

In general, for $\mathrm{ESPM}^{3}$, containing any number of maturity levels, the $\mathrm{i}^{\text {th }}$ maturity level, that is $\mathrm{M}_{\mathrm{i}}$, is defined as

$$
M_{i}=\bigcup_{j=2}^{i-1}\left\{M_{j}-M_{c}\right\} \cup\left\{\bigcup_{k=1}^{m} \operatorname{KPA}_{i k}\right\} \cup M_{c}
$$

where $\mathrm{i}, \mathrm{j}, \mathrm{k}$ and $\mathrm{m}$ are natural numbers, $\mathrm{M}_{\mathrm{c}}$ is the continuous improvement process group of KPAs and $\mathrm{KPA}_{\mathrm{ix}}$ is the $\mathrm{x}^{\text {th }}$ process area associated within the $\mathrm{i}^{\text {th }}$ level.

KPAs for level 3 are normally developed once level 2 has been reached and the organization concerned intends to reach level 3. In this model specific to the Mauritius context and guided by respondent classification summarised in Table 1, the following KPAs are developed at level 3:

- Human Resource management $\left(\mathrm{KPA}_{31}\right)$

- Risk management $\left(\mathrm{KPA}_{32}\right)$

- Contract management $\left(\mathrm{KPA}_{33}\right)$

Instantiation of the KPAs at level 1, 2 and 3 leads to the arrangement of the KPAs depicted graphically in Figure 7.

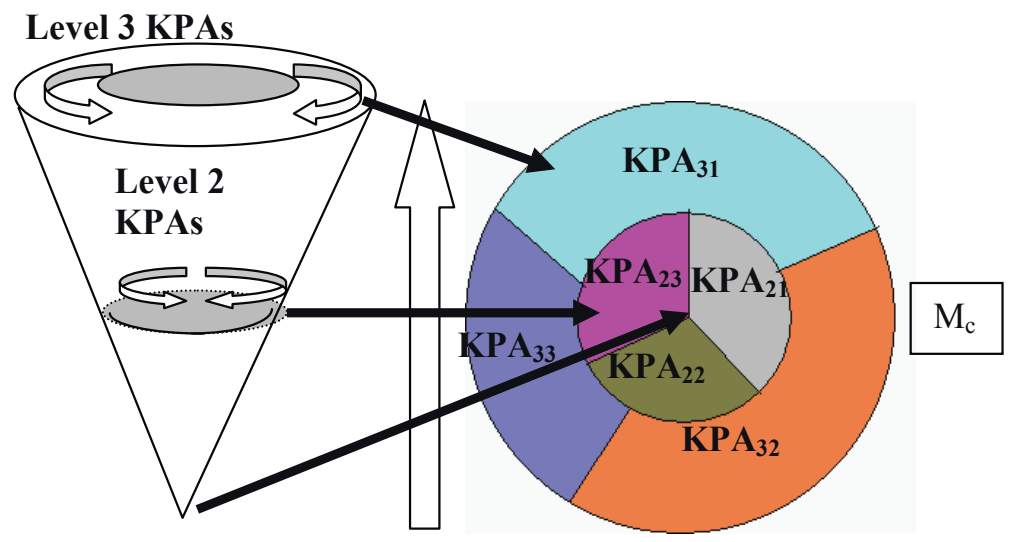

Figure 7: Instantiated representation of KPAs at level 1,2 and 3

Substituting for $\mathrm{m}$ in formula (5) defines $\mathrm{M}_{3}$ for $\mathrm{ESPM}^{3}$ as:

$$
M_{3}=\bigcup_{i=1}^{3} \mathrm{KPA}_{3 \mathrm{i}} \quad \mathrm{U} \quad \mathrm{M}_{2}
$$


Here $\mathrm{KPA}_{21}, \mathrm{KPA}_{22}$ and $\mathrm{KPA}_{23}$ are the key process areas that attained maturity at level $2\left(\mathrm{M}_{2}\right)$, while $\mathrm{KPA}_{31}, \mathrm{KPA}_{32}$ and $\mathrm{KPA}_{33}$ are the key process areas that attained maturity at level 3 . In general, therefore, KPAs at level i evolve after efforts are made to reach level i from level $\mathrm{i}-1$. Thus, any $\mathrm{KPA}_{\text {in }}$ for valid values of $i$ and $n$, matures at level $i$.

An organization is, however, not prevented from developing and using a KPA at a higher level, for example an organization at level 2 may include a KPA of level 3 should this KPA be considered important. Note that the organization cannot claim to be at the higher level if this happens, but it can be referred to as an extended level. For example, an organization at level 2 which is using a KPA of level 3 will be referred to as level 2-extended.

\section{Mapping of KPAs to the PDCA cycle}

As mentioned before, each KPA is mapped to the PDCA cycle. This is shown in Figure 8.

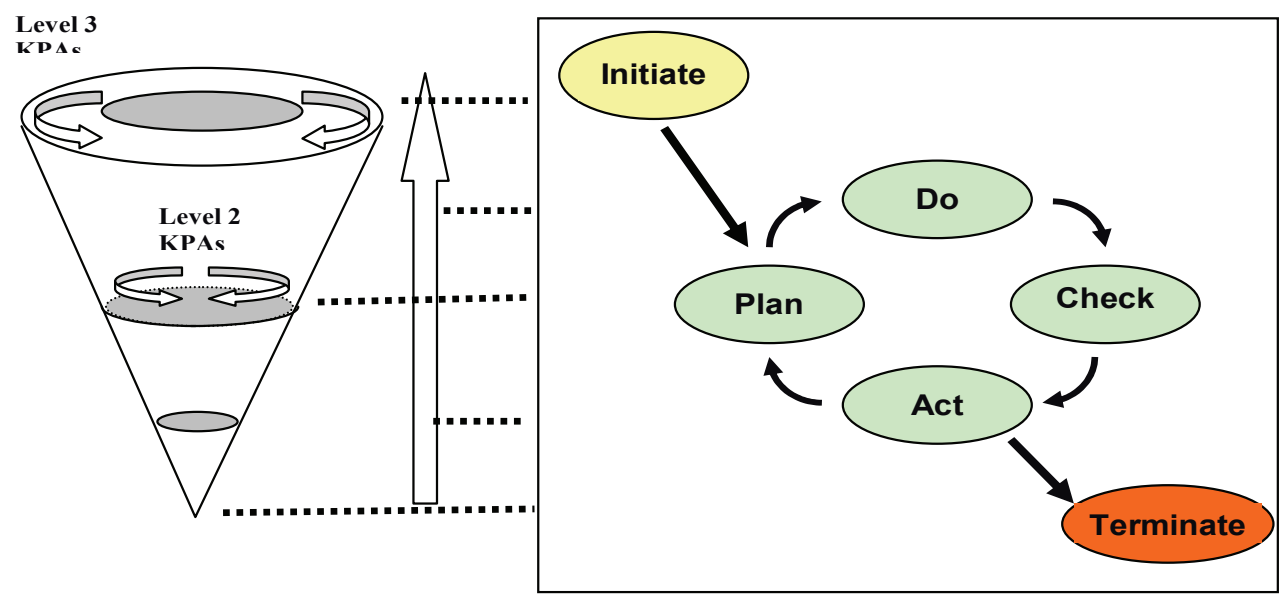

Figure 8: Mapping of KPAs to the PDCA cycle

\section{Suitability of ESPM ${ }^{3}$ for Mauritius}

The proposed $\mathrm{ESPM}^{3}$ addresses the problem of human resources, soft skills, contract management as well as software specificities. It also takes into consideration the political, social, economic and cultural aspects associated with software project management. In the Mauritian context, it allows software development organizations to focus on a few KPAs initially (for example 3 KPAs till maturity level 2 is reached) and subsequently adding more KPAs to progress to the next higher level (that is level 3). An organization at a lower level may also include a KPA of a higher level and enable it to operate at the extended lower level. The continuous process improvement group comprises those KPAs that affect KPAs at levels 2 and 3. For example, Integration management binds all KPAs in a coherent manner and the Environmental management KPA makes use of the political factor, when relevant, to influence Time management. The Software specific focused KPA influences the way project management is carried out for software development, example prototyping is considered as an important aspect in software development. KPAs are mapped to the Plan-Do-Check-Act process group as per ISO 9001:2000 requirement (Mauritian Standard, 2001). PMBOK ${ }^{\circledR}$ and CMMI include numerous KPAs (in the case of PMBOK, the KPAs called knowledge areas are further subdivided into 44 processes) to be considered and therefore the implementation of such methodologies is time consuming and renders 
the software development process complex in the Mauritian context. Thus, the $\mathrm{ESPM}^{3}$ is an attempt to reduce much of the bureaucracy associated with other models.

The evolutionary process is better shown in $\operatorname{ESPM}^{3}$ (for example in figure 1) than in CMMI.

The next section shows the application of $\mathrm{ESPM}^{3}$ to a project in the Mauritian context.

\section{Case Study}

A case study is included below to test the applicability of the ESPM ${ }^{3}$. It should be noted that each KPA is applied using the Plan-Do-Check-Act cycle that is a requirement of ISO. Each KPA is planned, executed, monitored and corrective actions are taken. However, due to time and space constraints, these specific details are omitted from this paper.

\section{Allowance Computation System}

This project comprises the selection of candidates for payment of an allowance earmarked for the low-income population group of Mauritius. An allowance amounting to US\$ 1.3 as proposed for needy beneficiaries of basic pensions (Basic Retirements Pension, Basic Widow Pension, Basic Invalidity Pension and Basic Orphan Pension). This project was chosen because of its political, social and economic attributes.

The implementation of the system had to be carried out at the earliest possible time during the financial year 2006/2007 given the political benefits to be derived and the relief it ought to provide to this segment of the population.

This project comprised tasks encompassing analysis, design, software development, implementation and training.

The company responsible for the development of the software and its implementation endeavoured to make use of CMMI in the past already and was, therefore, familiar with progression from one maturity level to the next. The ESPM ${ }^{3}$ was tested for the development of the software. All the KPAs were applied.

The following estimates were initially made:

Time frame: The estimated time frame for completion of the project was 5 weeks

Proposed start date and end date: 11 August 2006 to 14 September 2006

Estimated no. of person days: 64 person days.

Results obtained from implementation of the proposed ESPM ${ }^{3}$ showed encouraging results as described below:

\section{- Level 2 KPAs}

- Time management:

A Work Breakdown Structure (WBS) was applied to estimate the time to complete the project in terms of person-months. Historical data was used to estimate the time to complete similar tasks obtained from the WBS (time estimation by analogy).

Human resources had to be made available given the political pressure exerted. The environmental KPA dealing with the political aspect was considered. This involved the planning process for highly skilled software developers to be deployed on the project. A contingency plan was also devised to redeploy developers from other projects. 
The $\mathrm{ESPM}^{3}$ supports Time management by rendering the various tasks along a timeline using a Gantt chart. The actual progress could be verified against the planned progress and corrective action was initiated as soon as a significant deviation was noted.

Given the high power distance, resulting from the organization having tall organizational and/or report structures, it was important for the project leader to report problems to the head of the user organization in order not to delay the project. An example of a problem that had to be solved in this way was the frequent change in requirements by users interacting with the software developers. In the software development organization, the project leader acted as a facilitator for the project in addition to shouldering the responsibilities of the project.

- Cost management:

Using the set of components produced from the WBS, the cost of the software was estimated by taking into consideration the total number of person-months calculated during Time management.

- Quality management:

An evolutionary prototype was developed and user feedback was gathered and taken into consideration. This approach was not always adopted by the organization previously.

\section{- Level 3 KPAs}

- Human Resource management:

Given the importance of the project to be delivered on time, efforts had to be made to carefully select staff possessing the required skills and experience. Some staff also had to be transferred from other projects. It was, however, not possible to prevent some developers to simultaneously work on multiple projects. Therefore, some staff had to work for extra hours and payment of overtime could not be avoided.

- Risk management:

The main elements of risks included unavailability of key staff during the project, noncompliance to the terms of the contract and misunderstandings between the client and developers. The risks were evaluated in terms of severity of impacts and prioritized accordingly.

The Project Leader himself carried out the task of Risk management by ensuring that necessary human resources were adequate. Non-compliance to the terms of the contract could result mainly in the payment of a penalty fee. Misunderstandings were cleared up promptly with the use of the evolutionary prototype. The main issues that required action were arrangements of data fields in terms of a logical flow on the screen.

It was noted that the risks were successfully dealt with by the Project Leader.

Uncertainty avoidance, that is the extent to which ambiguous situation or uncertainty is avoided, was high in order to prevent any schedule overrun. However, the adoption of such a stand by the software organization concerned was necessary, that is, it was not possible to use new tools and techniques with which the staff had little or no experience for this project as no delay could be entertained. 
- Contract management:

A standard contract was signed between the company and the client and the Project Leader ensured compliance to the terms mentioned. Such a contract was a normal procedure for the company.

However, $\mathrm{ESPM}^{3}$ showed a new approach to handle Contract management with the mapping of the KPA to the PDCA cycle.

\section{- Continuous Improvement Process group of KPAs}

- Soft Skills management:

According to the Project Leader, the use of soft skills (such as good communication skills, team building, stress management and conflict management) has always been practiced by him and excellent results were obtained. It was not difficult to have staff working extra hours on projects. Staff members were discouraged from taking leave for the duration of such a project owing to the commitment of the company towards the successful implementation of the project that was considered of importance to assist the needy segment of the population as well as the reputation of the company. The staff responded positively to the request of the Project Leader.

However, according to the Project Leader, it is a known fact that Mauritian employees show a strong concern for family and social commitments. The environmental management KPA dealing with the social aspect was found to be important.

- Change management:

The major problem encountered was that users kept changing their requirements throughout the duration of the project. It was important to have top management involvement to prevent a schedule overrun. Given the tall organization structure of the user and software development organizations, it was necessary to deal directly with higher officers to clear misunderstandings in some cases. Senior organization officers were also encouraged to participate in evaluation of prototypes.

- Software specific focus:

Use of reusable code was encouraged by interaction between developers on various projects and this task was facilitated by the Project Leader. This contributed a lot to reduction in development time.

- Integration management:

Integration Management, being an important KPA could not be disregarded for the project. Its application ensured that the other KPAs were well coordinated in order to deliver the project successfully.

- Environmental management:

It was noted from the above explanation that this KPA influenced other KPAs like Time management, Human Resource management and Soft skills management.

The visibility of tasks was enhanced with simple tools and techniques like the use of WBS, Gantt charts and an evolutionary prototype (that is, providing a software specific focus). High priority was given to the project due to the political pressure exerted. Skilled developers had to be allocated to the project and a contingency plan had to be devised for deployment of additional staff. The project manager had to use soft skills and recognise the collectivist nature (in terms of extended family ties) of the staff in order to motivate them. Therefore, the company had to manage 
its human resources carefully so as not to delay other projects. Power distance, that is the extent to which power in an organisation was unequally distributed, was high and problems had to be resolved by the Project Leader by raising issues rapidly upward in the user organization and at the same time assuming responsibility thereof.

Soft skills management has an effect on Human Resource management. In addition to managing changes with respect to the project, Change management is also expected to induce and manage changes in all other KPAs. Software specific focused KPAs also affect other KPAs - example Time management may be enhanced with new software tools. The continuous improvement group of KPAs could only show positive effects over some period of time.

The advantage of $\mathrm{ESPM}^{3}$ was that there was no need for formal, long duration training for the project leader to apply the methodology. One session of face-to-face discussion and guidance by phone were enough. Furthermore, all the KPAs were applied successfully.

It was possible for the Project Leader to use both ESPM ${ }^{3}$ and CMMI concurrently. According to the Project Leader, ESPM ${ }^{3}$ was simpler and did not involve bureaucratic procedures as in the case of CMMI.

\section{Conclusions and Future Work}

This paper briefly referred to some of the problems experienced by Mauritius as a developing country with respect to delivery of successful projects. Mauritius is trying to develop its ICT sector as a pillar of its economy with the result that software development projects are growing rapidly in number. Based on earlier research, it was shown that project management methodologies of European/Western origins are not universally applicable (Muriithi \& Crawford, 2003). In addition, previous work carried out by Sukhoo et al. (2004a) and Sukhoo et al. (2005b) illustrated that this was also the case in Mauritius. The problems faced by Mauritius were considered and a case study for the applicability of $\mathrm{ESPM}^{3}$ was reported on.

The ESPM $^{3}$ provided a simple and flexible evolutionary approach for managing software development projects by portraying the evolutionary development of KPAs and at the same time rendering conceptually an integrated management process. The software specific focused KPA laid special emphasis on software projects by considering the strengths and weaknesses of such projects (Sukhoo et al, 2004b). The soft skills KPA was included to emphasize the importance of human relationships in management of software projects (Sukhoo, Barnard, Eloff, \& Van der Poll, 2005a). In addition, KPAs were considered with particular attention to economic, cultural, social and political aspects to attain successful delivery of software projects.

The ESPM ${ }^{3}$ was tested on three projects and one such project was reported on by means of a case study scenario as part of this paper. As future work, this model may be applied and improved further for larger projects. In addition, the progressive evolution of KPAs from one level to another can be portrayed by using $\mathrm{ESPM}^{3}$ over a longer duration.

\section{References}

Aladwani, A. M. (2002). IT Project uncertainty, planning and success: An empirical investigation from Kuwait. Information Technology and People. 15 (3), 210-226.

BPO Secretariat - Board of investment. (2005). Survey on the ITES BPO sector in Mauritius.

Central Computer and Telecommunications Agency [CCTA]. (2002). Project management industry initiatives. Retrieved December 12, 2002, from http://www.ogc.gov.uk/prince/progmgtbrief1997.pdf

CMMI Product Team (2002). Capability Maturity Model Integration. Retrieved January 3, 2006, from http://cmsu2.cmsu.edu/public/classes/sam/cis4655/cmmi.pdf 
Eid, A. (2002). Cyber Island, Silicon Valley under the tropics. Islander. 32, 66-67.

Gray, C. F. \& Larson, E. W. (2000). Project management: The managerial process. Singapore: Mc GrawHill.

Hughes, B. \& Cotterell, M. (2006). Software project management. (4 ${ }^{\text {th }}$ ed.). London, UK: McGraw-Hill.

Kwak, Y. H. (2003). Brief history of project management. Retrieved September 19, 2005 from http://home.gwu.edu/ kwak/PM_History.pdf

Management Audit Bureau Website (2005). ISO 9001 Implementation. Retrieved January 4, 2006 from http://www.gov.mu/portal/site/mabsite/menuitem.b4fa590d611ae5b397da581065c521ca/

Mauritian Standard (2001). Quality management systems - Requirements. Mauritius Standards Bureau.

Muriithi, N. \& Crawford, L. (2003). Approaches to project management in Africa: Implications for international development projects. International Journal of Project Management, 21(5), 309-319.

PMBOK Guide (2004). Third edition excerpts. Retrieved January 3, 2006 from http://www.pmi.org/info/pp_pmbok2k_conf.asp

Rao, M.T. (2004). Key issues for global IT sourcing: Country and individual factors. Information Systems Management, 21(3), 16-21.

State Informatics Ltd Website (2006). SIL's Quality Policy. Retrieved December 8, 2006 from http://sil.intnet.mu/Achievements/quality.htm

Stuckenbruck, L.C. \& Zomorrodian, A. (1987). Project management: The promise for developing countries. International Journal of Project Management, 5(3), 167-175.

Sukhoo, A., Barnard, A., Eloff, M.M. \& Van der Poll, J.A. (2004a). A survey of project management tools, techniques and methodologies used in Mauritius: The current status. Proceedings of the 2004 PMSA Global Knowledge Conference, 320-329.

Sukhoo, A., Barnard, A., Eloff, M.M. \& Van der Poll, J.A. (2004b). Towards a framework for evaluating strengths and weaknesses of software projects. Proceedings of the 2004 PMSA Global Knowledge Conference, 193-199.

Sukhoo, A.; Barnard, A.; Eloff, M.M. \& Van der Poll, J.A. (2005a). Accommodating soft skills in software project management. Journal of Issues in Informing Science and Information Technology, 2, 691-704. Available at http://2005papers.iisit.org/I55f42Sukh.pdf

Sukhoo, A., Barnard, A., Eloff, M.M. \& Van der Poll, J.A. (2005b). An assessment of software project maturity in Mauritius. Journal of Issues in Informing Science and Information Technology, 2, 671-690. Available at http://2005papers.iisit.org/I54f41Sukh.pdf

Wideman, R. M. (2005). PMBOK Guide ( $3^{\text {rd }}$ ed.) - Is more really better? Retrieved January 3, 2006 from http://maxwideman.com/papers/pmbok3/pmbok3b.pdf

\section{Appendix - Questionnaire}

\begin{tabular}{|l|l|}
\hline \multicolumn{2}{|c|}{ Interview Questionnaire on the use of Software Project Management Maturity Model } \\
\hline 1. & $\begin{array}{l}\text { Is your organization currently making use of a Maturity Model (MM)? If yes, pro- } \\
\text { ceed to question } 2 \text { otherwise proceed to question 4. }\end{array}$ \\
\hline 2. & Which type of MM (general or software specific) is your organization using? \\
\hline 3. & What are the problems that you encounter with the MM used in your organization? \\
\hline 4 & $\begin{array}{l}\text { Are you in favour of a software project management maturity model in particular } \\
\text { v/s a general project management maturity model? Explain why yes / no. }\end{array}$ \\
\hline
\end{tabular}




\begin{tabular}{|c|c|}
\hline 5. & $\begin{array}{l}\text { Maturity models make use of key process areas or focus areas in order to deter- } \\
\text { mine the maturity level of an organization. Are the following KPAs (or focus ar- } \\
\text { eas) important and should it ideally be considered by a software project maturity } \\
\text { model: } \\
\text { - Time management } \\
\text { - Budget management } \\
\text { - Quality management } \\
\text { - Human Resource management } \\
\text { - Risk management } \\
\text { - Soft skills management } \\
\text { - Contract management } \\
\text { - Change management } \\
\text { - Software specific focus } \\
\text { - Integration management }\end{array}$ \\
\hline 6. & $\begin{array}{l}\text { Do you think that other KPAs are also important for software project management } \\
\text { in Mauritius? If so, list other KPAs and briefly explain why you consider them to } \\
\text { be important. }\end{array}$ \\
\hline 7. & $\begin{array}{l}\text { What are the features that you believe to be important in these KPAs that need to } \\
\text { addressed? }\end{array}$ \\
\hline 8. & $\begin{array}{l}\text { Many maturity models in use (like Kerzner's maturity model, Capability Maturity } \\
\text { Model (CMMI) and Microframe's self assessment tool) have five maturity levels. } \\
\text { Do you think that a MM with less maturity levels will assist more companies in } \\
\text { Mauritius to adopt it? }\end{array}$ \\
\hline 9. & $\begin{array}{l}\text { How would you arrange the KPAs in question } 5 \text { above as well as any other KPAs } \\
\text { identified in question } 6 \text { in different maturity levels taking into consideration the } \\
\text { number of levels envisaged as per question } 8 \text { ? }\end{array}$ \\
\hline 10. & $\begin{array}{l}\text { Do you think continuous process improvement is important while dealing with } \\
\text { KPAs or do they have to remain as static areas of a MM. }\end{array}$ \\
\hline 11. & $\begin{array}{l}\text { Mauritius has a shortage of skilled manpower in the field of ICT. In your opinion, } \\
\text { what are the possible solutions? }\end{array}$ \\
\hline 12. & $\begin{array}{l}\text { Some studies have revealed the influence of culture (based on Hofstede's dimen- } \\
\text { sion as well as dealing with cross cultural aspects), economic situation, political } \\
\text { situation (projects that have political benefits are given priority, social conditions } \\
\text { (low wages - tendency to supplement with part time employment, poverty, family } \\
\text { ties). Do you believe that the introduction of one or more KPAs dealing with } \\
\text { these issues will assist in the management of software projects in Mauritius? Why } \\
\text { yes or no? }\end{array}$ \\
\hline
\end{tabular}




\section{Biography}

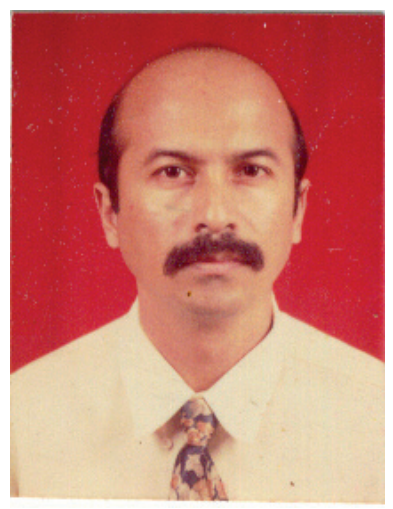

Aneerav Sukhoo works as Acting Deputy Director for the Central Informatics Bureau, Ministry of Information Technology \& Telecommunications in Mauritius. He has 17 years of experience in the IT field, out of which 10 years in IT project management, in dealing with implementation of IT projects in the Public Service. He has a B.Sc Honours degree in Computer Science from the University of South Africa (Unisa) and a Master of Information Technology degree from Charles Sturt University. He is presently preparing a $\mathrm{PhD}$ thesis at the University of South Africa for the development of a software project management methodology.

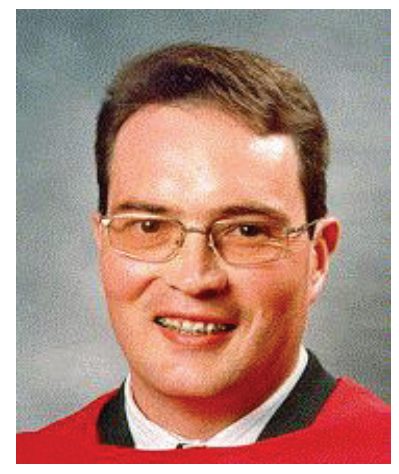

Andries Barnard, Associate Professor in the School of Computing at Unisa, holds a PhD (Computer Science). He teaches undergraduate courses in automata theory and formal languages and roject management, as well as postgraduate courses in project management and research methodology. His research interests include computer ethics and graph grammar languages.

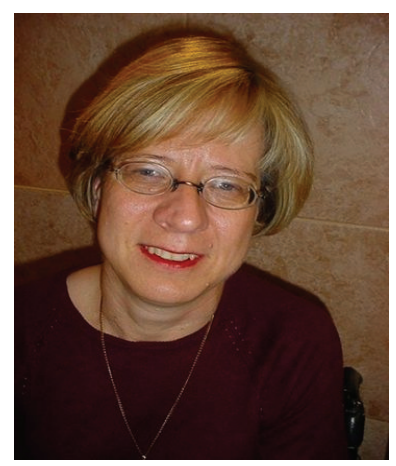

Mariki M. Eloff received a PhD Computer Science degree from the Rand Afrikaans University (RAU), South Africa. She has presented research papers at international and national conferences focusing on information security. She joined Unisa as an associate professor in the School of Computing at Unisa in October 2002. She has assisted in the organisation and management of international conferences in information security and has been part of the ISSA Conferences since its inception in 2000. Her research interests include computer security and project management.

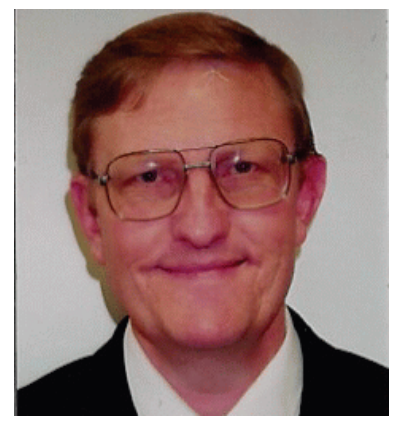

John A. Van der Poll is a full professor in the School of Computing at Unisa. He holds a PhD in Computer Science and teaches an undergraduate course in operating systems, as well as postgraduate courses in compiler construction and formal program verification. His research interests are in formal specification techniques and automated reasoning. 